\title{
A escravidão como berço do Brasil contemporâneo
}

Wesley Sousa Sampaio

SOUZA, J. A elite do atraso: da escravidão à lava-jato. Rio de Janeiro: Leya, 2017.

Em 2018, a movimentação política, o conflito entre os poderes, o surgimento de presidenciáveis ultraconservadores, o crescimento de manifestações e discursos de ódio e a descrença no Estado são as pautas das rodas de conversas em grupos, mídias sociais e sites de notícia que configuram a aura de inquietação que paira neste atual momento de eleições. Já expressivas no processo eleitoral de 2010, agravaram-se em 2014.

Jessé Souza ${ }^{1}$ se dedica a estudar o pensamento social, a desigualdade e as classes sociais no Brasil contemporâneo. Em sua obra A Elite do Atraso, da escravidão à Lava Jato, parte do pressuposto de que a ideia dominante é a da "classe dominante" (MARX; ENGELS, 1998), e analisa a formação do senso comum que propicia o surgimento de homens "incorruptíveis", os quais travam verdadeiras cruzadas contra a corrupção do Estado. Estes "templários" são a classe média, na posição de "exército" particular da elite financeira - a "Elite do Atraso", segundo o autor. Munido de uma linguagem espontânea, Jessé estabelece um diálogo com o leitor, manifestando suas inquietações e preocupações em uma análise de conjuntura ousada. Por meio de ironias, propõe

1 Mestre em Sociologia pela Universidade de Brasília, doutor em Sociologia pela Karl Ruprecht Universität Heidelberg, e Pós-Doutorado em Filosofia e Psicanálise na New School for Social Research de Nova Iorque.

\section{$\overline{\text { Wesley Sousa Sampaio }}$}

Graduando em Ciências Sociais pela Universidade Estadual do Ceará. E-mail: wesley.s.sampaio@hotmail.com 
outra perspectiva do pensamento sociológico brasileiro, buscando incitar uma nova ótica sobre a contemporaneidade.

Sérgio Barreira de Faria Tavolaro² (2005) apresenta uma análise crítica a duas vertentes do pensamento nacional: a sociologia da herança patriarcal/patrimonial e a sociologia da dependência. A primeira, em busca de um elo pré-moderno que componha a "essência" da relação público/privado, guia-se pelo princípio de uma pessoalidade com a coisa pública, ligado ao sistema colonial e seus vestígios na formação cultural. Tem como seus principais autores Gilberto Freyre, Sérgio Buarque de Holanda, Raymundo Faoro e Roberto DaMatta. A segunda estuda a empresa colonial em seus aspectos econômicos, e desenvolve uma narrativa estrutural das relações de classes. Seus principais autores são Caio Prado Jr., Florestan Fernandes, Fernando Henrique Cardoso e Octávio Ianni.

Jessé Souza, por sua vez, seria representante da sociologia da dependência por sua crítica às ideias de patrimonialismo e populismo, predominantes no senso comum como justificativas para o atraso do Brasil. O autor não se limita a observar um culturalismo de pessoalidade com a coisa pública, que teria seu berço no centralismo da imagem do patriarca. Para ele, este centralismo está na origem de uma estrutura de classes favorável à atuação da elite financeira. Convenientemente, os argumentos de Holanda e Faoro legitimariam a existência dessa elite e configurariam o verdadeiro espectro de crises econômicas, sociais e políticas em todo o trajeto histórico, como também as atuais.

Em busca de resposta aos questionamentos: De onde viemos? Quem somos? Para onde vamos?, Jessé Souza examina obras clássicas de intelectuais brasileiros e se propõe a desconstruir a ótica patrimonialista, em prol da perspectiva de análise das classes sociais e do mercado financeiro.

Inicia por Gilberto Freyre, apreendendo a dimensão central de suas narrativas, as relações de poder ou hierarquias e as trocas e os condicionamentos de classes por meio da observação das práticas sociais. Souza argumenta que a base metodológica de Freyre

2 Professor na Universidade de Brasília, graduado em Ciências Sociais e Mestrado em Sociologia pela Universidade Estadual de Campinas, Mestrado e Doutorado em Sociologia pela The New School for Social Research de Nova Iorque. 
é de vital importância para a análise do processo histórico, mas, ao minimizar as relações de violência, oculta aspectos do processo de dominação. Contudo, por meio desta base empírica Jessé identifica a categoria de sadomasoquismo, que, como um processo de intimidação, violação, disciplina e miscigenação exercido pela figura política do senhor de engenho, é apresentada em CasaGrande \& Senzala (FREYRE, 2003) e rompe com o ideário de papeis ativos das raças na formação da sociedade brasileira, defendido por Freyre. Portanto, em A Elite do Atraso vemos "Freyre contra ele mesmo" (SOUZA, 2017): ao tempo em que defende a intercambialidade da relação das raças, apresenta dados empíricos que podem ser usados para refutar sua tese. A escravidão é definida por Jessé como berço desta sociedade, tendo aspectos de uma "instituição total", responsável pela contaminação e destituição de uma identidade (GOFFMAN, 1974). Apropriando-se dos escritos do próprio Freyre, demonstra os aspectos estruturais que compõem a legitimidade da dominação e resultam na formação de uma "ralé de novos escravos", coletivo social pertencente às classes mais baixas e visto por Souza como uma continuidade da escravidão no Brasil moderno.

A falta de assistência para integração, profissionalização e planejamento urbano pelo Estado lançava esta ralé a desempenhar atividades braçais, fabris e proletárias, além de induzir o surgimento de favelas. Como podemos perceber, a violência contra estas massas marginalizadas nas metrópoles brasileiras foi iniciada nas senzalas. Este conjunto de fatores colabora para um estado de anomia, dificultando a interação entre membros da mesma classe ou etnia. O sociólogo propõe uma análise das desigualdades que não se limite aos parâmetros econômicos. Acredita que as desigualdades são construtos sociais mais complexos, e desconsidera a possibilidade do mercado como meio de emancipação e mobilidade social. A classe social, tomada por ele um fenômeno sociocultural, permite-lhe afirmar que o preconceito de classe está diretamente ligado ao de raça.

Jessé Souza elenca quatro classes principais que compõem a Sociedade brasileira: a elite dos proprietários, a classe média e suas frações próprias, a classe trabalhadora semiqualificada e a 
ralé de novos escravos. Dentre todas, a classe média desempenha um papel marcante por seu vínculo com a elite. Para o autor, esse "pacto antipopular" dissociativo quanto às camadas trabalhadoras, estabelecido por estas duas frações, tem início na Era Vargas. Com a conduta desenvolvimentista e reformista e em coalisão com as elites, Getúlio Vargas iniciou o processo de industrialização, prosseguido por Juscelino Kubitschek em 1950, e adotou estratégias que beneficiaram a classe trabalhadora, como a Consolidação das Leis do Trabalho (CLT). Assim, esta classe é reforçada, ficando à mercê da elite e seu ideário, devido à existência de uma classe menor da qual se diferencia, ou seja, a ralé que permaneceu desfavorecida e intocada por não representar relevância aos projetos políticos. Em busca de ainda favorecer as elites, o desenvolvimento da imprensa e do ensino superior atendeu à demanda mercadológica, estando diretamente associado às elites e seus diferentes capitais econômicos, culturais e sociais.

O capital econômico ou financeiro é tido como o mais importante, por permitir que a elite econômica compre as outras elites que desfrutam dos demais capitais; o capital cultural é indispensável para a reprodução do capitalismo, sendo o tipo mais "democratizado"; o capital social consiste nas relações e vínculos que são criados no decorrer da competição pelos outros dois tipos. Porém, houve uma colonização da classe média e da esfera pública pelo dinheiro. Se a elite do dinheiro (proprietários) se diferencia pelo monopólio do capital financeiro, a classe média se define pela "reprodução do capital cultural sob a forma de conhecimento útil" (SOUZA, 2017, p.129). Esse "conhecimento" é elaborado pela academia sob o espectro de teorias "pseudocríticas" e difundido pela imprensa, conformando o discurso da esfera pública.

As categorias de patrimonialismo, estigmatizadas na década de 1920 com o movimento tenentista, e, posteriormente, de populismo na representação de Getúlio Vargas, reverberam pelas mídias e tornam-se fundamentais para a análise de conjuntura. Jessé reconhece em Sérgio Buarque de Holanda e Raymundo Faoro os conceitos que constroem a visão de mundo liberal. O patrimonialismo será visto como equivalente funcional da corrupção do Estado pelo "homem cordial"; a demagogia e o populismo, 
como representações de classes populares inaptas a participar da esfera pública por sua imoralidade e produção cultural e material simplória. Para a opinião pública, nos moldes de uma racionalidade burguesa, o próprio mercado aparece como incorruptível e autorregulável. Portanto, a iniciativa privada, o empreendedorismo, a meritocracia e os diferentes capitais são postos como antagônicos à corrupção do Estado brasileiro e às demandas ilegítimas da ralé.

Para Jessé, as reflexões de Buarque de Holanda tanto legitimam o Estado corrupto como "o mal maior da nação" (SOUZA, 2017, p.132) quanto apostam na figura do "homem cordial" para negligenciar as problemáticas sociais e os condicionamentos materiais. A universalidade de uma conduta própria do brasileiro, assumida posteriormente por Faoro ao traçar uma trajetória histórica que a justifica, é responsável por substituir a análise da luta de classes e sua origem no regime escravocrata pela censura ao governo. Isso porque o estudo do patrimonialismo e do populismo nas universidades confere o ideal de objetividade e prestígio científico, tendo ainda maior peso na formação da opinião pública. Desse modo, a vida política é encenada em meio a golpes de Estados, incitados pela elite do dinheiro com o auxílio da imprensa e da classe média. É a criação de uma "corrupção dos tolos" tendo em vista ocultar a "corrupção real", que é a manutenção das desigualdades.

A Lava Jato surge como reação ao governo petista e seu líder maior, Lula. Segundo Jessé, o objetivo é combater a diminuição das fronteiras entre classes. As políticas sociais e internacionais deste governo estavam voltadas às massas populares, e começavam a afetar uma das principais dimensões da dominação: a indústria cultural, por meio do ingresso dos pobres nas universidades. A classe média, em suas frações - a liberal, a crítica e a protofascista -, apesar de suas divergências, linhas de pensamento e apropriação das categorias de análise, manifestam similaridades em seus discursos: o moralismo e a crítica ao Estado. Isso, para Jessé, justificaria as mobilizações entre 2013 e 2016, que se iniciaram com a organização midiática da fração protofascista e resultaram no agrupamento de coletivos diferenciados em defesa de 
pautas variadas, mas contra o governo da então presidenta Dilma Rousseff.

A disputa entre os poderes e a exaltação do judiciário na figura "Do Juiz", com o objetivo de deslegitimar o executivo, nada mais foi do que um mecanismo de reação da elite financeira desfavorecida pela conduta do governo petista. Ao fazer uso do seu monopólio da esfera pública, na sua "novelização infantilizada dos conflitos políticos" (SOUZA, 2017, p.200), mobiliza as massas da classe média em favor da mantença de status e privilégios, sob o disfarce do moralismo conservador e da diminuição do Estado em favor do mercado.

A elite do dinheiro se sobressai quanto às demais. Dentre todas as formas de legitimação ou as diferentes bancas parlamentares que se manifestam em favor próprio, acima de latifundiários, políticos, juízes e funcionários públicos, temos o capitalismo financeiro agindo de forma espontânea e desenfreada. Para esta elite, realmente é vantajoso o fortalecimento de um culturalismo manifesto em uma privatização da esfera pública.

Mas onde estamos em todo esse contexto? Qual nosso grau de responsabilidade? Reconhecendo seu papel de produtor da indústria cultural, Jessé Souza, ao criticar os clássicos do pensamento nacional e assumi-los como sistematizadores de categorias ou ideários, inclui a si mesmo nesta reflexão, e, por que não dizer, também a seus leitores. Desta forma, convida-nos a assumir nossas responsabilidades, nossos crimes e nossos preconceitos. Posiciona-se em prol de reformular as ciências sociais e seu modo de pensar o Brasil, dialogando com o que já foi produzido, reconhecendo suas faltas ou equívocos, renovando as categorias de análise e reformulando a identidade nacional. Não tem a pretensão de estabelecer novos paradigmas de imediato, mas de desenvolver a reflexão necessária para a metamorfose. Propõe o exercício de espantar-se com o comum e o familiar e desafiar o que se tornou incontestável.

Em sua busca por desconstruir paradigmas e forçar a reflexão, Jessé Souza é ousado. Sua insatisfação pessoal com o todo ao seu redor (e talvez consigo mesmo) se expressa no radicalismo de sua fala explícita, da ironia do título da obra ao uso de "dedos 
apontados". Uma narrativa frenética, jovial, envolvente e desafiadora, sem esquecer a seriedade de um texto acadêmico. Jessé escreve para os pensadores, porém rejeita seu vocabulário rebuscado. Na onda de violência física e simbólica que assola nossas mídias e espaços de convivência, legitimada por um culturalismo assassino, uma obra tão agressiva quanto, todavia oposta, faz-se necessária. Acredito que A Elite do Atraso é uma centelha que tem por objetivo inflamar discussões e debates. Assume em um período tão tenebroso o papel de instigar a polêmica e o desafio de pensar além das fronteiras teóricas já existentes, voltar o olhar ao passado, ao trajeto histórico e aos nossos pilares epistemológicos. Nascemos na escravidão, somos o que a nossa esfera pública denomina "cidadãos de bem". Ainda assim, Jessé propõe a reflexão e a autocrítica sobre nossa identidade para pensarmos em nosso futuro.

\section{REFERÊNCIAS}

FREYRE, G. Casa-grande e senzala: formação da família brasileira sob o regime da economia patriarcal. 48. ed. Pernambuco: Global, 2003.

Sobrados e mucambos. 3. ed. Rio de Janeiro: José Olympio Editôra, 1961.

GOFFMAN, E. Manicômios, prisões e conventos. São Paulo: Perspectiva, 1974.

MARX, K.; ENGELS, F. A ideologia alemã. Tradução de Luis Claudio de Castro e Costa. São Paulo: Martins Fontes, 1998.

TAVOLARO, S. B. F. Existe uma modernidade brasileira?: reflexões em torno de um dilema sociológico brasileiro. RBCS, v. 20, n. 59, p.5-22, out. 2005. 